\title{
IMAGENS DO NECROCAPITALISMO NO BRASIL: A INDÚSTRIA MINERADORA DE NIÓBIO
}

\author{
Ana Flávia Martins de Lima ${ }^{1}$ \\ Cíntia Rodrigues de Oliveira ${ }^{2}$
}

\begin{abstract}
RESUMO
Este registro fotográfico teve como objetivo capturar os mundos de morte resultantes de práticas necrocapitalistas de acumulação de capital na indústria do nióbio e a resistência das populações tradicionais no município de Catalão, Goiás. A partir da análise de documentos e do material fotográfico foi possível caracterizar as práticas de acumulação como crimes corporativos perpetrados em um contexto de exploração neocolonial marcado pela subalternidade do Estado a grandes corporações justificado por meio do discurso do desenvolvimento cujos efeitos englobam a expropriação das comunidades, a destruição dos meios de vida e a resistência das populações tradicionais.
\end{abstract}

Palavras-Chave: necrocapitalismo, nióbio, crime corporativo

\section{IMÁGENES DEL NECROCAPITALISMO EM BRASIL: LA INDUSTRIA MINERA DE NIÓBIO}

\section{RESUMEN}

Este registro fotográfico tuvo como objetivo captar los mundos de la muerte resultantes de las prácticas necrocapitalistas de acumulación de capital en la industria del niobio y la resistencia de las poblaciones tradicionales en el município de Catalão, Goiás. A partir del análisis de documentos y material fotográfico fue posible caracterizar las prácticas de acumulación como delitos corporativos perpetrados en un contexto de explotación neocolonial, marcado por la subordinación del Estado a las grandes corporaciones justificadas a través del discurso del desarrollo cuyos efectos incluyen la expropiación de comunidades, la destrucción de medios de vida y la resistencia de poblaciones tradicionales.

${ }^{1}$ Doutoranda em Administração Pública e Governo na Fundação Getúlio Vargas, São Paulo.

2 Professora Doutora do PPGAdm/FAGEN/UFU. 
Palabras clave: necrocapitalismo, nióbio, crime corporativo

\title{
IMAGES OF NECROCAPITALSM IN BRAZIL: THE MINING INDUSTRY OF NIÓBIO
}

\begin{abstract}
This photographic record aimed to capture the worlds of death resulting from necrocapitalist practices of capital accumulation in the niobium industry and the resistance of traditional populations in the municipality of Catalão, Goiás. From the analysis of documents and photographic material it was possible to characterize the accumulation practices as corporate crimes perpetrated in a context of neocolonial exploitation marked by the subordination of the State to large corporations justified through the discourse of development whose effects include the expropriation of communities, the destruction of livelihoods and the resistance of traditional populations.
\end{abstract}

Keywords: necrocapitalism, niobium, corporate crime

\section{INTRODUÇÃO}

As corporações são as instituições mais poderosas do mundo (ROSS, 2017), e, ainda que sejam uma criação recente na história do mundo, sua onipresença em nossas vidas mostra o quanto elas são inerentes à sociedade. Elas produzem os químicos presentes no ar que respiramos e na comida que comemos, assim como as drogas que utilizamos para nos mantermos saudáveis, e são ainda centrais aos sistemas de saúde, justiça, educação e transporte (TOMBS; WHITE, 2015).

A perspectiva das organizações como sistemas responsáveis pela produção e distribuição de bens e serviços, independentemente das consequências danosas de sua atuação que, muitas vezes, representam um risco à sociedade, tendo em vista que protagonizam crimes graves, por vezes marcados por mortes, destruição do meio ambiente e desapropriação de comunidades, serve também para ocultar interesses escusos, como a manutenção do capitalismo contemporâneo. 
Um exemplo dessa perspectiva é o setor de mineração. Em anos recentes - 2015 e 2019 - o Brasil vivenciou os dois maiores crimes corporativos da história do país, ambos envolvendo a indústria mineradora. Em novembro de 2015, o rompimento da barragem do fundão em Bento Rodrigues - MG matou 19 pessoas e espalhou 650km de rejeitos de mineração pelo Rio Doce (MEDEIROS, 2018). Menos de 5 anos depois, no dia 25 de janeiro de 2019, ocorreu outro rompimento de barragem de rejeitos da Vale, em Brumadinho - MG, que provocou a liberação de 13 milhões de metros cúbicos de lama, matando mais de 320 pessoas, em sua maioria, trabalhadores que almoçavam no restaurante da empresa localizado a $2 \mathrm{~km}$ da barragem (PEREIRA et al., 2019).

É nosso interesse neste ensaio fotográfico documentar imagens que podem servir de uma forma de ativismo social voltada para envolver a audiência acadêmica em um diálogo engajado para desnaturalizar os crimes corporativos como um fenômeno incidental e disfuncional.

Desse modo, pretendemos que este ensaio fotográfico contribua para a ampliação das discussões sobre as corporações no campo dos estudos organizacionais para além dos seus aspectos superficiais, reclamando a desnaturalização das corporações e o aprofundamento da discussão crítica sobre essas instituições.

O ensaio se desenvolve ao observar como as imagens ajudam na criação de uma narrativa em que a angústia e a dor são centrais, introduzindo o enredo de sofrimento e a perda das comunidades. As imagens são interpretadas com base no conceito de necrocapitalismo proposto por Banerjee (2008) para descrever um conjunto de práticas de acumulação de capital em contextos coloniais que envolvem a desapropriação, morte, tortura, suicídio, escravidão e destruição dos meios de vida através do conluio entre Estado e corporação, no interior de uma economia política de extração de recursos baseada em formas coloniais de desenvolvimento (SRIKANTIA, 2016). Para oferecer um entendimento sobre tais práticas, discutimos a teorização de Banerjee (2008) no contexto da indústria mineradora de nióbio no município de Catalão, Goiás. 
0 Brasil detém 98,2\% das reservas de nióbio do mundo e é responsável pelo atendimento de $93 \%$ do consumo mundial. Os principais importadores do nióbio brasileiro são a China, América do Norte e União Europeia (CBMM, 2019). Seis Lagos, no Pará, representa 47\% das reservas mundiais do minério; Araxá; em Minas Gerais, 15\%; e Catalão, em Goiás (GO), 1\% (CBMM, 2019).

A atividade extrativista do nióbio no país é concentrada em duas grandes corporações: a Companhia Brasileira de Metalurgia e Mineração (CBMM) e a Niobrás, antiga subsidiária da Anglo American vendida à China Molybdenum (CMOC) em 2016 por 1,7 bilhões de dólares (CMOC, 2016). Em 2018, o faturamento das empresas foi de 7,4 bilhões de reais (CBMM, 2018) e 2,72 bilhões de reais respectivamente (CMOC, 2018).

A exploração de nióbio no município de Catalão, GO, inicia-se em 1970, com a fundação da Mineração Catalão S.A., empresa do grupo majoritariamente alemão Brasimet. Em 1976, entra em atividade a mina de nióbio no Complexo Catalão I (Mina 1). Em 1983, a empresa é vendida a Anglo American que passa a explorar o Complexo Catalão II (Mina 2) conhecido como Mina Boa Vista, localizada próximo as comunidades Macaúbas, Coqueiros e Mata Preta (SOUSA et al., 2019). Em 2009 a Anglo American anunciou redução de 25\% dos custos de pessoal e venda de ativos, entre eles a Copebrás, mineradora de fosfato e a Niobrás, antiga Mineração Catalão S.A. (PORTAL CATALÃO, 2009). Em 2016, as empresas são adquiridas por 1,7 bilhões de dólares pela China Molybdenum (CMOC) (CMOC, 2016).

Os principais problemas associados a exploração do nióbio no município estão relacionados a expulsão das famílias do campo, a modificação da dinâmica hídrica na região em decorrência da perfuração de poços e do aprofundamento da mina de extração e a deterioração das condições de vida das populações das comunidades próximas as mineradoras que atuam na região.

De acordo com o laudo 002/2015 emitido pela Secretaria Municipal de Meio Ambiente (SEMMAC), a grande movimentação de caminhões e máquinas e a detonação de explosivos associados a operação na Mina Boa Vista provoca degradação da qualidade do ar. A 
amostragem dos níveis de ruídos emitidos na operação das máquinas na mina Boa Vista também apresenta resultados acima dos limites recomendados. De acordo com o laudo, "a ocorrência de ruídos altos, principalmente aqueles com caráter impulsivo (gerados pelas explosões), provocam danos e desequilíbrios ao ecossistema local, especialmente à fauna" (SEMMAC, 2015, p. 13). Conforme consta no documento, os moradores indicam a permanência dos ruídos também no período noturno.

Os resultados obtidos com o monitoramento mostraram que, "de fato, a transformação causada pela atividade minerária é intensa e atua de forma prejudicial não somente sobre a comunidade Coqueiros, mas também sobre as comunidades vizinhas, onde persistem as mesmas queixas" (SEMMAC, 2015, p. 14).

Além dos problemas ambientais, em novembro de 2018, após auditoria do Departamento Nacional de Produção Mineral (DNPM), foram constatados débitos das mineradoras que operam no município relativos a Compensação Financeira pela Exploração de Recursos Minerais (CFEM) no valor de 94 milhões de reais e ao Imposto sobre Serviços de Qualquer Natureza (ISSQN) no valor de 15 milhões de reais (PORTAL CATALÃO, 2018).

No dia 29 de outubro de 2018, o então prefeito da cidade, Adib Elias, bloqueou ferrovias e vias de acesso à CMOC com maquinários da Prefeitura Municipal em retaliação a mineradora (JORNAL OPÇÃO, 2018). Em resposta às acusações de sonegação de impostos, a CMOC divulgou nota no dia 29 de outubro de 2018 em que alega "cumprir na íntegra e de forma rigorosa com todas as obrigações tributárias e quaisquer outras obrigações conforme legislação, nos âmbitos municipal, estadual e federal” (JORNAL OPÇÃO, 2018, p. 3).

A exploração do nióbio em Catalão também é alvo de denúncias e Ações Civis do Ministério Público do Estado. Em 25 de setembro de 2019 o Promotor Roni Alvacir Vargas proibiu o Governo do Estado de conceder nova outorga de uso da água para a mineradora Niobrás, "pois não monitora a captação de água de seus cursos hídricos e aquífero, muito menos a vazão mínima a ser mantida para assegurar o uso múltiplo da água, não sendo 
razoável valer-se, exclusivamente, das informações e dados fornecidos pelas empresas" (MINISTÉRIO PÚBLICO DO ESTADO DE GOIÁS, 2019a, p. 1).

Também em junho de 2019, o Ministério Público do Estado exigiu na justiça, por meio de Ação Civil Pública, a desativação da barragem de rejeitos 1A da Niobrás e a proibição por parte do Estado de conceder licença de instalação para obras de alteamento das barragens de rejeitos $1 \mathrm{~A}, 1 \mathrm{~B}, 2 \mathrm{~A}$ e $2 \mathrm{~B}$ da referida empresa. Também ficou determinada a remoção de instalações administrativas localizadas a jusante das barragens. De acordo com matéria publicada no site do Ministério Público (2019b, p. 1), "as barragens possuem alto dano potencial associado, inclusive com possibilidade de atingir dezenas funcionários que trabalham em instalações situadas à jusante das barragens".

Os estudos da SEMMAC, as investigações do Ministério Público e a auditoria do DNPM evidenciam a existência de crimes ambientais e evasão fiscal na exploração do nióbio. Esses crimes devem ser compreendidos como práticas de acumulação necrocapitalistas tendo em vista que sua consecução está relacionada a busca pela redução permanente dos custos de produção e provocam a desapropriação, morte e destruição dos meios de vida e estão inseridos em uma política econômica colonial-extrativista. 0 contexto colonial-extrativista no qual ocorre a exploração do nióbio é evidenciada por sua vez na subalternidade do Estado retratada nos episódios de proibição de concessão de outorga de uso de água e das licenças de instalação das obras de alteamento das barragens de rejeitos da Niobrás pelo Ministério Público.

Como forma de justificar o avanço da atividade minerária as autoridades recorrem ao discurso do desenvolvimento econômico, expresso principalmente nas alegações sobre geração de impostos, renda e emprego. Ao considerarmos o histórico de evasão fiscal das grandes mineradoras no município de Catalão, G0, devemos questionar a real contribuição da atuação dessas empresas para o desenvolvimento econômico na região.

Os moradores das comunidades atingidas, no entanto, possuem uma visão diferente do que significa a expansão da exploração de minério. Como forma de convencer os moradores 
da importância de impor resistência ao avanço da atividade minerária, um dos moradores da Comunidade Macaúbas elaborou a metáfora da porteira, narrativa sobre a perda de poder e autonomia das comunidades diante da atuação de grandes corporações multinacionais.

$\mathrm{Na}$ imagem 1 podemos observar a pequena porteira recostada sobre a muda e o cupinzeiro e ao fundo a montanha de rejeitos de minério. A pequena porteira de milho crioulo é uma contraposição quase heroica à enorme montanha de rejeitos que simboliza o poder e a capacidade de intervenção do capital sobre a disposição e as formas de uso e não uso do território.

Imagem 1. Metáfora da porteira.

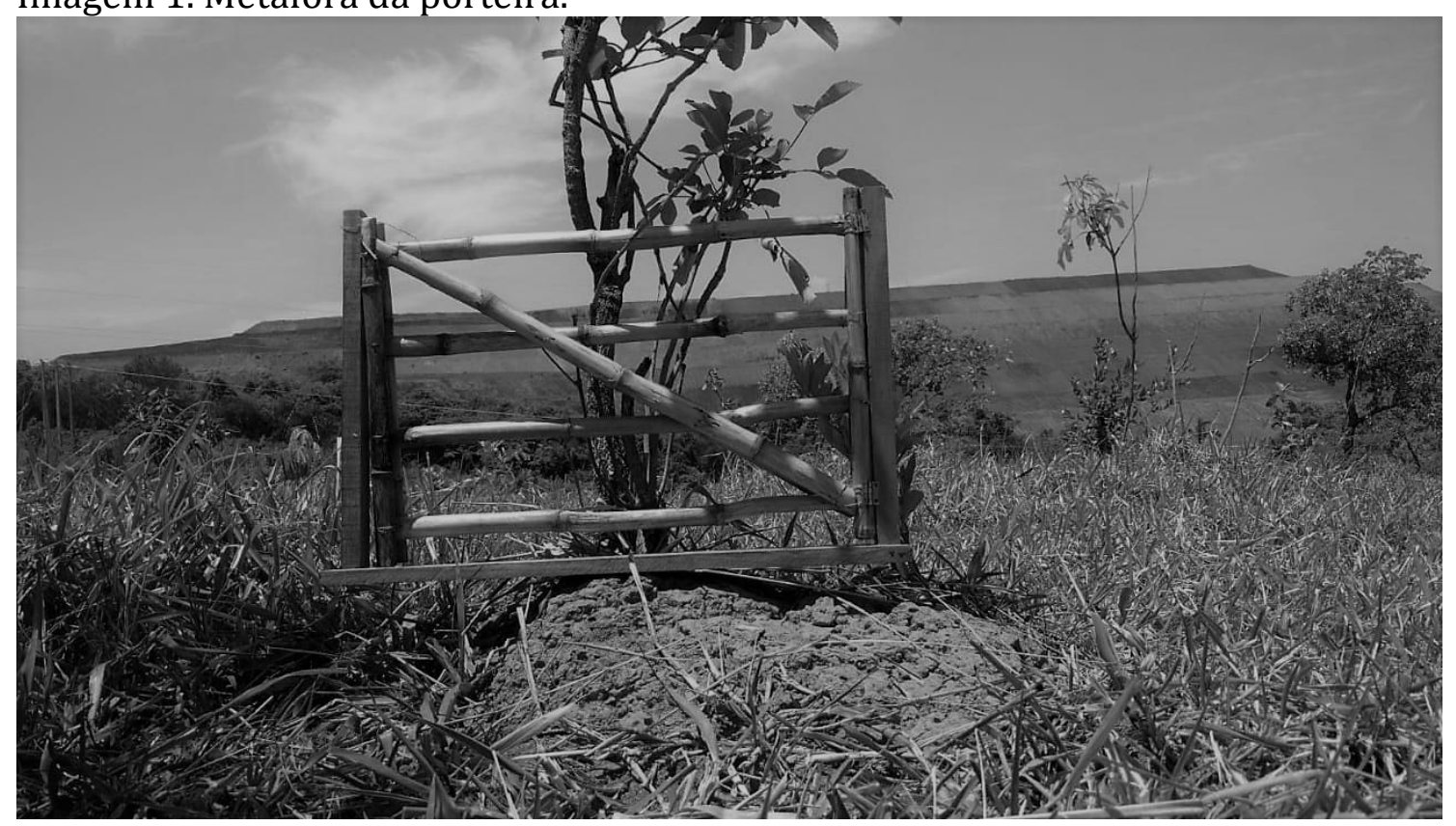

Fonte: Autores.

A porteira pode ser compreendida como expressão da autoridade e autonomia das populações tradicionais sobre o território e também como recurso simbólico que nos remete a cultura caipira. A metáfora da porteira representa a dominação exercida pelas corporações multinacionais. Em última instância corresponde a uma denúncia do modelo de exploração colonial que permanece estruturando as relações econômicas entre os países, mais do que isso é uma convocação à resistência e a retomada do controle das populações tradicionais sobre seus territórios. 
As populações atingidas no contexto da exploração do nióbio se constituem fundamentalmente por pequenos agricultores que dependem dos recursos naturais para sua reprodução material e simbólica. Dessa maneira, a deterioração das condições de vida dessas populações está relacionada a destruição e apropriação do território por grandes corporações multinacionais, pela perda do lar, da cultura e da comunidade, ou seja, a imposição de uma condição de aniquilamento simbólico e material que acaba por transformá-las em mortosvivos (MBEMBE, 2016).

Talvez a expressão mórbida mais impactante da mineração seja a mina de extração. A mina é uma grande vala de onde é retirada a vida e onde são enterradas a história, a tradição e os vínculos de uma população. A mina é a lacuna, o vazio, a falta, a suspensão de vida. 0 buraco tão vazio e ao mesmo tempo tão pesado, um fardo carregado não só pelos que tiveram que deixar suas terras, mas também pela sociedade como um todo. No contexto da exploração do nióbio, a mina é a expressão mais evidente dos mundos de morte produzidos pelas práticas necrocapitalistas. 
Imagem 2. A grande vala.

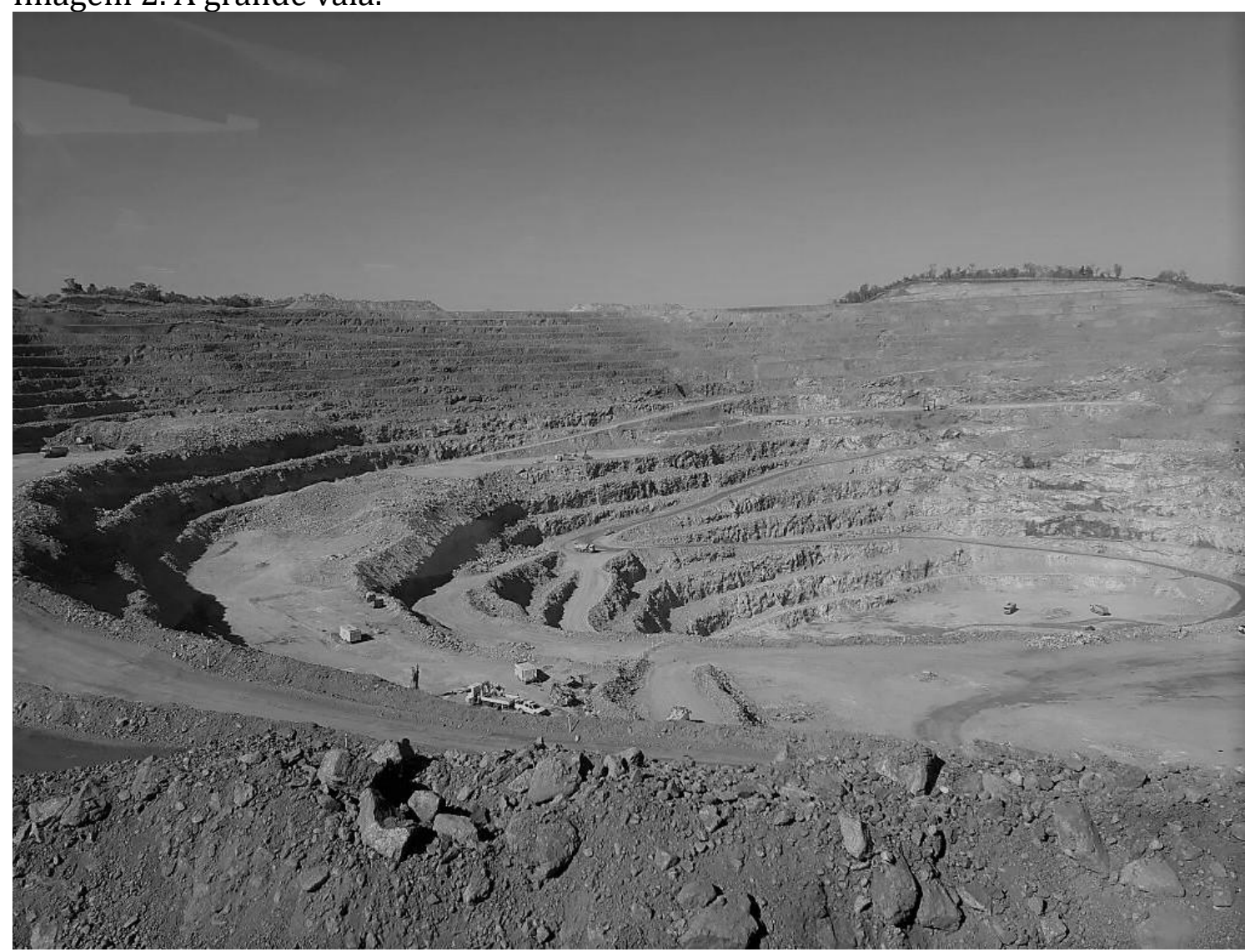

Fonte: Autores.

A imagem é incapaz de reproduzir a dimensão da destruição. Se olharmos com atenção podemos observar alguns veículos ao longo das linhas que contornam a mina. Tratam-se dos caminhões que transportam o material para a planta de beneficiamento, localizada no município de Ouvidor, GO, próximo a Comunidade Macaúbas. A grandiosidade da destruição fica mais evidente quando observamos a imagem do caminhão em uma perspectiva aproximada conforme a imagem 3 . 


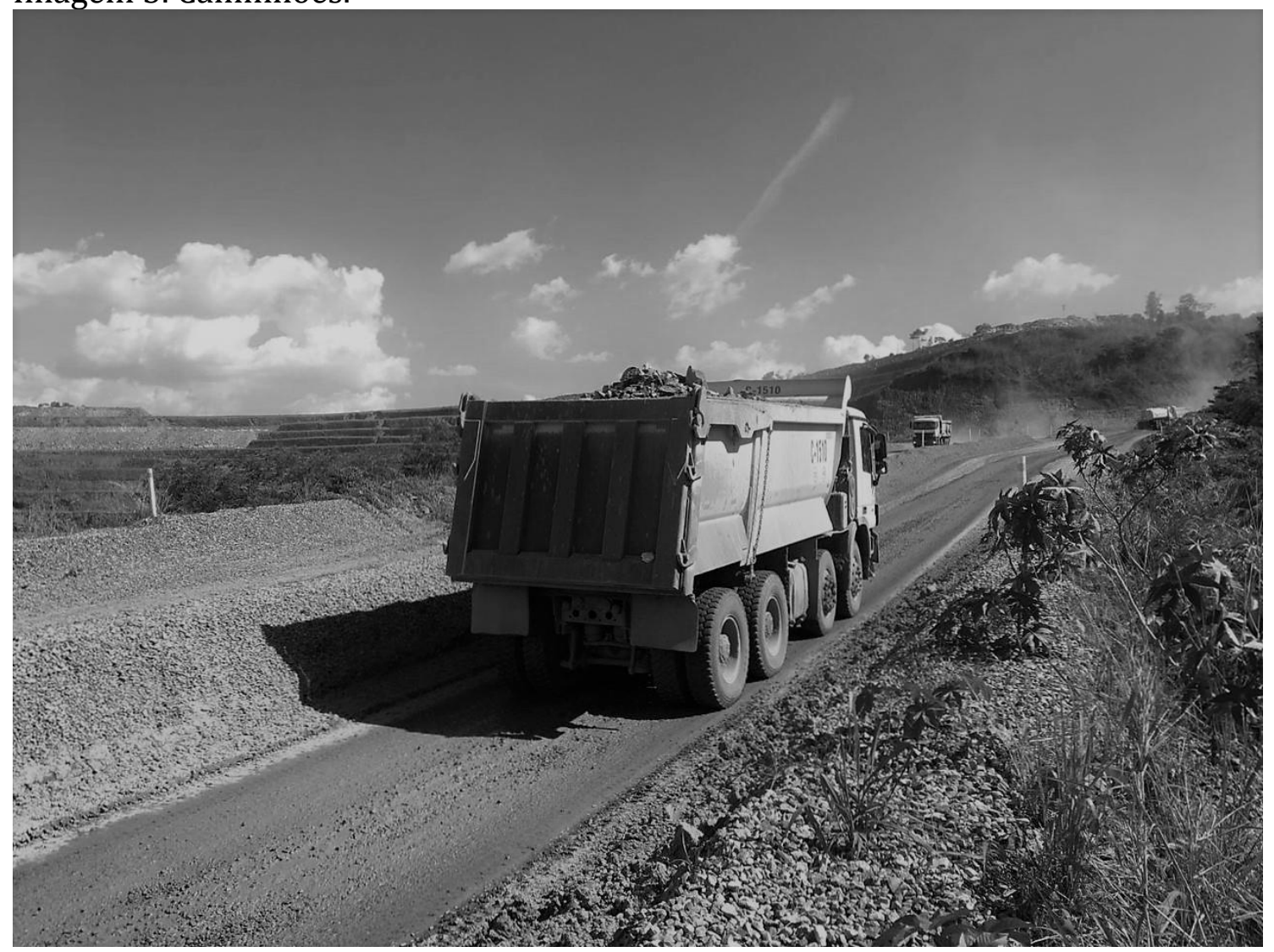

Fonte: Autores.

Centenas de caminhões como os retratados na imagem acima carregam diariamente toneladas de material até a planta de beneficiamento localizada no município vizinho, Ouvidor, GO, de forma ininterrupta. 0 tráfego intenso de caminhões provoca uma série de impactos ambientais e a deterioração das condições de vida dos moradores, sobretudo devido a poluição sonora e atmosférica resultantes. A fotografia representa a intervenção da máquina no território e os efeitos devastadores que essa intervenção impõe aos moradores das comunidades por meio da eliminação ou comprometimento dos recursos naturais, fundamentais para a reprodução material e simbólica dessas comunidades.

A expansão da atividade minerária se realiza em detrimento das pessoas por meio da apropriação do território pelas mineradoras, ilustrada na imagem 4. 


\section{RBEG}

Revista Brasileira de

Estudos Organizacionais
Ana Flávia de Lima e Cíntia Oliveira

Imagens do Necrocapitalismo no Brasil: a Indústria Mineradora de Nióbio

Imagem 4. Apropriação do território.

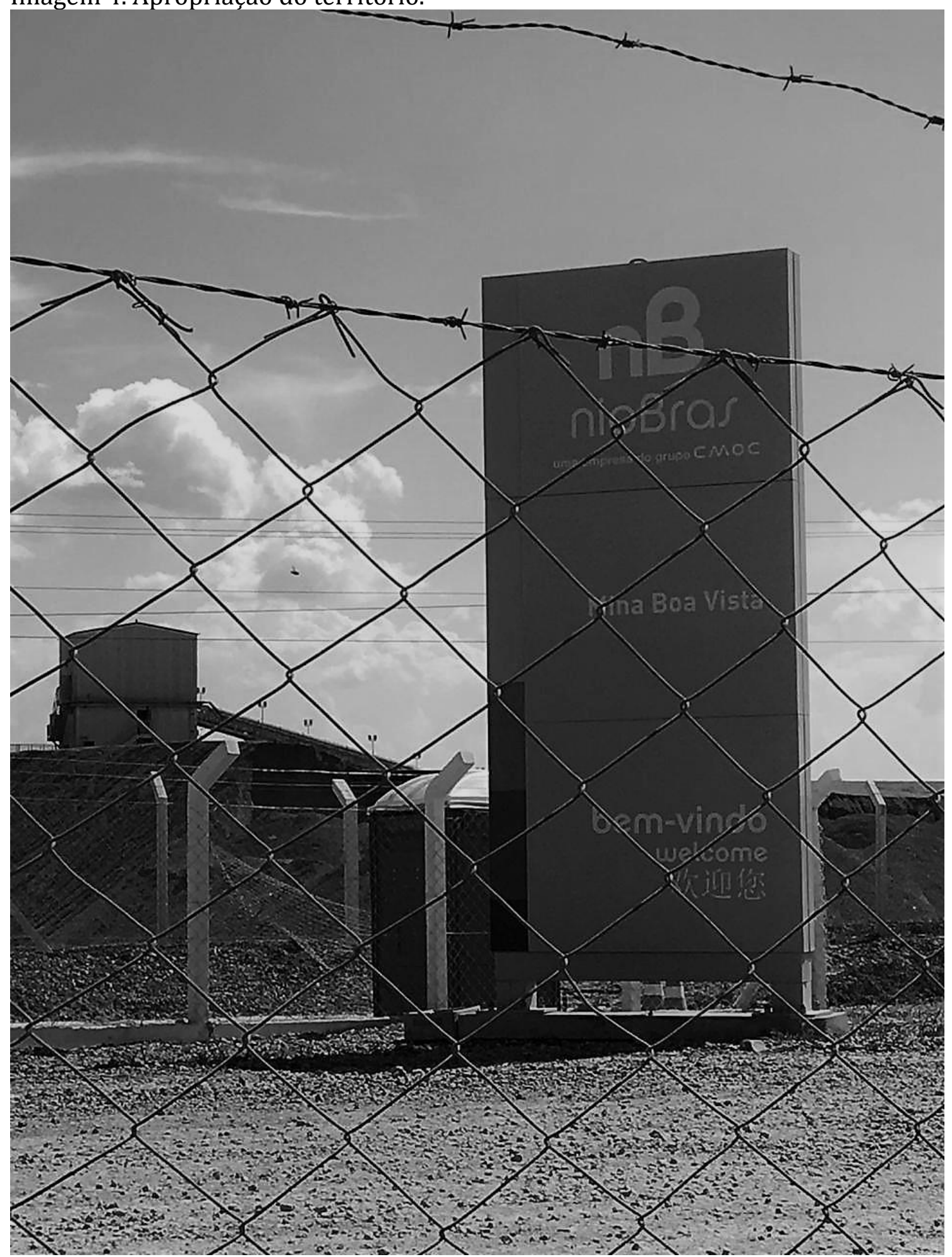

Fonte: Autores. 
A fotografia refere-se a placa de designação da planta de beneficiamento da Niobrás. Ao fundo é possível observar parte da estrutura que compõe a planta cercada por dois alambrados. No primeiro plano, observamos a placa com os dizeres "bem-vindo" em português, inglês e mandarim e no primeiro plano os arames farpados que se contrapõem ao enunciado da placa. Essa imagem é notadamente significativa para compreendermos a dinâmica da relação entre a mineradora e os moradores das comunidades. Expressa a tentativa de cercear, controlar, impedir o acesso ao território ao mesmo tempo em que transmite a mensagem de boas-vindas.

A apropriação do território deve ser reconhecida como um dos elementos que integram os mundos de morte produzidos no interior do modelo colonial de exploração do nióbio porque a apropriação leva a expulsão das famílias do campo e consequentemente a destruição de seus modos de vida. A desapropriação das famílias significa não só a perda da propriedade, mas, também, das formas de reprodução da existência que incluem as atividades de subsistência, o convívio social e a identidade cultural.

Em contraposição a expansão da atividade minerária e a apropriação do território, foi criado em 2018 um grupo de trabalho para discussão dos problemas envolvendo a mineração que conta com a participação de lideranças políticas, estudantes e moradores. A imagem 5 retrata uma das atividades de resistência promovida pelos moradores em parceira com a Universidade Federal de Goiás para recuperação das nascentes através do plantio de mudas nativas ao longo de uma ribanceira. 
Imagem 5. Resistência.

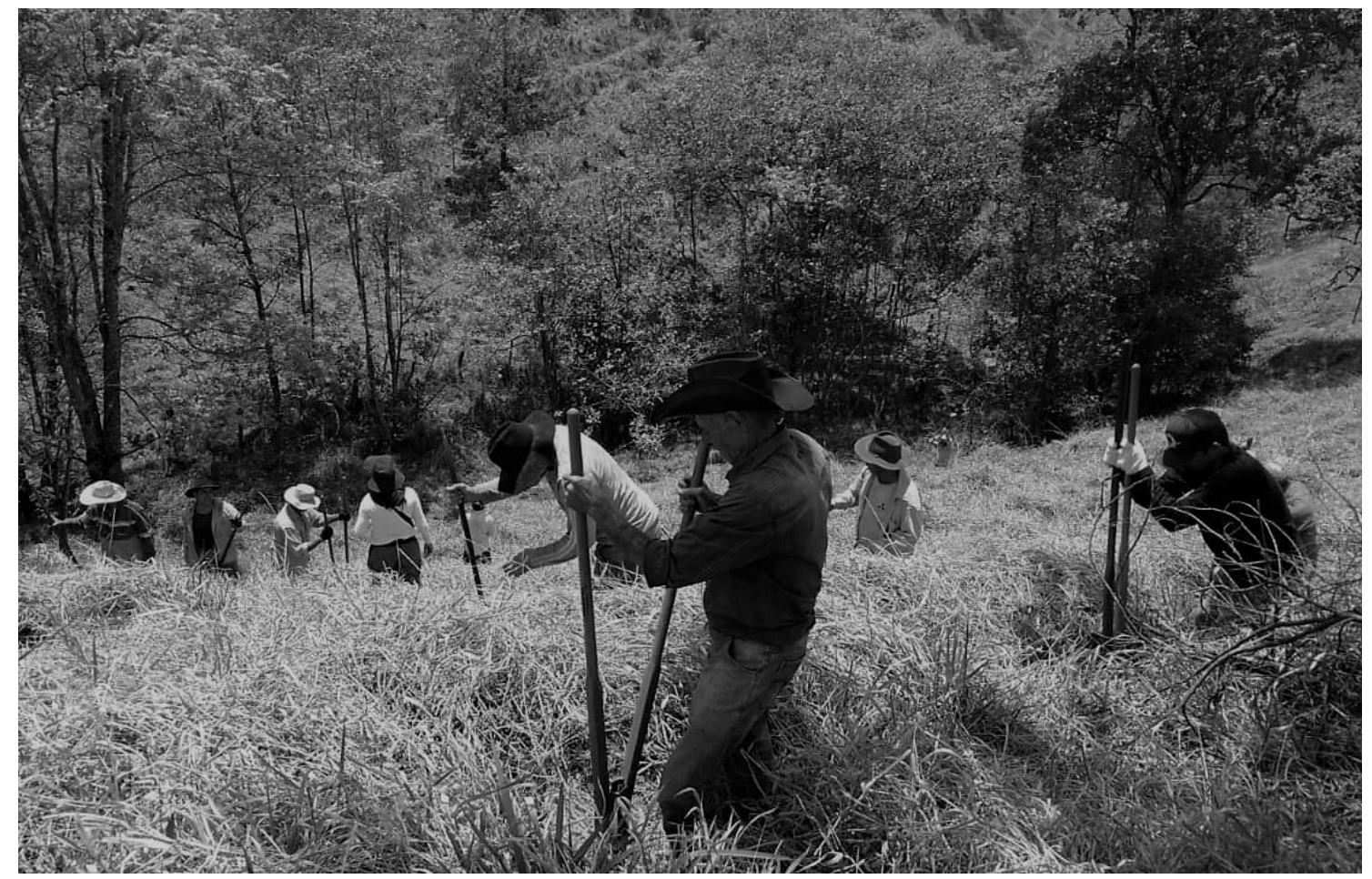

Fonte: Autores.

Os mutirões são uma tentativa de recuperar as nascentes soterradas pela atividade das mineradoras de maneira que os recursos hídricos possam voltar a ser abundantes na região. Essa atitude demonstra um desejo de permanência e cuidado com o território em contraposição a subalternidade do Estado. Diante do desamparo das autoridades e da iminência do aniquilamento simbólico e material imposto pelo avanço da mineração, os moradores recorrem a luta coletiva como forma de reivindicar condições mais favoráveis de permanência no território em reverência aos seus modos de vida, a sua cultura e comunidade.

\section{CONTRIBUIÇÃO FOTOGRÁFICA}

Através dos depoimentos e das fotografias foi possível fazer uma incursão sobre a realidade das comunidades afetadas pelas práticas necrocapitalistas de exploração do nióbio no município de Catalão, GO. A utilização de recursos fotográficos nos permitiu expor uma realidade que dificilmente seria acessada de outra maneira. As fotografias capturaram a 
essência do aniquilamento, da exceção e das formas de resistência que compõem o contexto de exploração colonial que se pretendeu analisar nesse ensaio.

Optamos pelas fotografias em preto e branco como forma não só de contrastar luzes e sombras, mas também para remeter o leitor à suspensão da vida. As fotos em preto e branco trazem uma dramaticidade e um aspecto documental que também procuramos explorar nesse ensaio. Por fim, as fotografias nos auxiliaram a visualizar as modificações físicas e simbólicas resultantes da exploração necrocapitalista do nióbio e a resistência dos moradores em contraposição a subalternidade do Estado a grandes corporações multinacionais.

\section{CONCLUSÃO}

Este ensaio pretendeu contribuir para a ampliação das discussões sobre a dominação econômica e política e para a compreensão dos efeitos das formas contemporâneas de exploração colonial sobre as populações tradicionais no contexto dos estudos organizacionais brasileiros. Para tanto recorremos a fotografia e a análise documental para compreendermos o modelo de exploração empregado pelas mineradoras e seus efeitos para as populações tradicionais.

A partir da análise podemos caracterizar o necrocapitalismo da indústria do nióbio enquanto práticas de acumulação realizadas por meio do crime ambiental e da evasão fiscal em um contexto de exploração neocolonial marcado pela subalternidade do Estado a grandes corporações cujo avanço da atividade minerária é justificado por meio do discurso do desenvolvimento - especificamente a geração de empregos e renda - e seus efeitos englobam a expropriação das comunidades, a destruição dos meios de vida e a resistência das populações tradicionais.

A dificuldade de acesso as instalações da mineradora foi uma limitação importante porque não pudemos fotografar as barragens de rejeitos citadas na Ação Civil Pública apresentadas na contextualização. Entretanto, tal limitação não emudece a denúncia social 
que se pretendeu realizar. A análise do material revelou aspectos da atividade minerária que nem mesmo a promessa do desenvolvimento econômico é capaz de superar.

É preciso reconhecer os danos causados pela mineração e questionar se o lucro produzido pela exploração do solo e das pessoas é mais importante do que a vida. É preciso que nós, pesquisadores estejamos dispostos a desvelar os mecanismos através dos quais a vida é subjugada em prol do lucro, que possamos desnaturalizar a existência das grandes corporações e reivindicar a emancipação das populações tradicionais e dos governos locais frente ao poder econômico, institucional e discursivo dessas instituições.

Nesse sentido, convidamos outros pesquisadores a avançarem o debate sobre o necrocapitalismo da indústria mineradora de nióbio a começar por recortes regionais distintos cuja análise poderá revelar aspectos que não puderam ser abordados nesse ensaio. Também caberá a pesquisas futuras determinar os prejuízos em termos econômicos e sociais da evasão fiscal no contexto específico da exploração de nióbio e por fim, recomendo estudos que visem aprofundar as discussões sobre os movimentos sociais e as formas de resistência das populações atingidas pela mineração.

\section{REFERÊNCIAS}

BANERJEE, Subhabrata. Necrocapitalism. Organization Studies, [s. l.], v. 29, n. 12, p. 15411563, 2008. https://doi.org/10.1177/0170840607096386

CBMM. Apresentação à Comissão de Minas e Energia. [S. 1.], 2019. Disponível em: https://www2.camara.leg.br/atividade-legislativa/comissoes/comissoespermanentes/ cme/audiencias-publicas/2019/09-07-2019-extracao-exploracao-comercio-eexportacao- doniobio-pl-4978-2013/3.\%20CBMM.pdf. Acesso em: 29 out. 2019.

CBMM. Relatório de Sustentabilidade. [S. l.], 2018. Disponível em: https://cbmm.com/assets/sustainability-report-2018/pdf/CBMM RS2018.pdf. Acesso em: 29 out. 2019. 
CMOC. CMOC adquire as operaçoes de nióbio e fosfato no Brasil. [S. 1.], 2016. Disponível em: http://cmocbrasil.com/br/noticia/cmoc-adquire-as-operacoes-de-niobio-efosfatos-no-brasil. Acesso em: 29 out. 2019.

CMOC. Conheça Alguns Números da CMOC. [S. l.], 2018. Disponível em: https://cmocbrasil.com/br/cmoc. Acesso em: 29 out. 2019.

JORNAL OPÇÃO. Mineradora responde acusações do prefeito de Catalão em nota. [S. l.], 29 out. 2018. Disponível em: https://www.jornalopcao.com.br/ultimas-noticias/mineradoraresponde-a-acusacoes-do-prefeito-de-catalao-em-nota145688/\#: :text=Mineradora\%20responde\%20a\%20acusa\%C3\%A7\%C3\%B5es\%20do\%20prefeito \%20de\%20Catal\%C3\%A3o\%20em\%20nota,segunda $\% 2$ Dfeira\%2029\&text=Depois $\% 20 \mathrm{de} \% 20$ bloqueio $\% 20 \mathrm{a} \% 20$ ferrovias,resposta $\% 20 \% \mathrm{C} 3 \% \mathrm{~A} 0$ \%20determina\%C3\%A7\%C3\%A3o\%20do\%20prefeitura. Acesso em: 26 nov. 2019.

MBEMBE, Achille. Necropolítica. Arte \& Ensaios - Revista do PPGAV/EBA/UFRJ, n. 32, p. 122151, 2016.

MEDEIROS, Cíntia Rodrigues de Oliveira.; SILVEIRA, Rafael Alcadipani da.; OLIVEIRA, Luciano Batista de. Mitos no desengajamento moral: retóricas da SAMARCO em um crime corporativo. Revista de Administração Contemporânea, Rio de Janeiro, v. 22, n.1, art. 4, 2018, p. 70-91. https://doi.org/10.1590/1982-7849rac2018160310

MINISTÉRIO PÚBLICO DO ESTADO DE GOIÁS. Ação do MP requer proibição de nova outorga do uso de água a mineradoras em Catalão e Ouvidor. [S. 1.], 25 jun. 2019. Disponível em: http://www.mpgo.mp.br/portal/noticia/acao-do-mp-requer-proibicao-de-nova-outorga-do-uso-deagua-a-mineradoras-em-catalao-e-ouvidor\#.Xy76gahKhEY. Acesso em: 26 nov. 2019a.

MINISTÉRIO PÚBLICO DO ESTADO DE GOIÁS. Promotor cobra na Justiça que mineradora de nióbio em Ouvidor esvazie barragens de rejeitos. [S. l.], 27 jun. 2019. Disponível em: http://www.mpgo.mp.br/portal/noticia/promotor-cobra-na-justica-que-mineradora-de-niobio-emouvidor-esvazie-barragens-de-rejeitos\#.Xy77IKhKhEY. Acesso em: 26 nov. 2019b. 
PEREIRA, L. F.; CRUZ, Gabriela de Barros; GUIMARÃES, R. M. F. Impactos do rompimento da barragem de rejeitos de Brumadinho, Brasil: uma análise baseada nas mudanças de cobertura da terra. Journal of Environmental Analysis and Progress, p.122-129, 2019. https://doi.org/10.24221/jeap.4.2.2019.2373.122-129

PORTAL CATALÃO. Anglo American põe ativos no Brasil à venda. [S. l.], 23 out. 2009. Disponível em: https://portalcatalao.com.br/portal/noticias/brasil/anglo-american-poeativos-no-brasil-a-venda,Nzk10Q.html. Acesso em: 26 nov. 2019.

PORTAL CATALÃO. Auditoria do DNPM confirma débitos de mineradoras com o município de Catalão. [S. $\quad$ l.], 06 nov. 2018. Disponível em: https://www.portalcatalao.com.br/portal/noticias/cidade/auditoria-do-dnpm-confirma-debitos-demineradoras-com-o-municipio-de-catalao,MjAzOTE.html. Acesso em: 26 nov. 2019.

ROSS, Jeffrey. Protecting democracy: a parsimonious, dynamic and heuristic model of controlling crimes by the powerful. Criminal Justice Studies, [s. l.], ano 2017, v. 30, ed. 3, p. 289-306. http://dx.doi.org/10.1080/1478601X.2017.1318132

SRIKANTIA, Jessica. The structural violence of globalization. Critical perspectives on international business, [s. l.], v. 12, ed. 3, p. 222-258, 2016. https://doi.org/10.1108/cpoib-09$\underline{2015-0040}$

SECRETARIA MUNICIPAL DE MEIO AMBIENTE. Laudo de constatação no 002/2015. [S.l.], 06 fev. 2016., Catalão, Goiás.

TOMBS, Steve; WHYTE, David. The Corporate Criminal: Why corporations must be abolished. 1. ed. Nova Iorque: Routledge, 2015. 214 p. 